Article

\title{
Analyzing the Coopetition between Tourism and Leisure Suppliers-A Case Study of the Leisure Card Tirol
}

\author{
Martin Schnitzer ${ }^{1}{ }^{*}$, Maximilian Seidl ${ }^{1}$, Philipp Schlemmer ${ }^{1}$ and Mike Peters ${ }^{2}$ \\ 1 Department of Sport Science, University of Innsbruck, Fürstenweg 185, A-6020 Innsbruck, Austria; \\ Maximilian.S.seidl@student.uibk.ac.at (M.S.); Philipp.Schlemmer@uibk.ac.at (P.S.) \\ 2 Department of Strategic Management, Marketing and Tourism, University of Innsbruck, \\ Karl-Rahner-Platz 3, A-6020 Innsbruck, Austria; Mike.Peters@uibk.ac.at \\ * Correspondence: Martin.Schnitzer@uibk.ac.at; Tel.: +43-0512-507-45865
}

Received: 30 March 2018; Accepted: 2 May 2018; Published: 7 May 2018

\begin{abstract}
Even though coopetition in the context of tourism is not new, research lacks concrete examples within the leisure business and about its effects on local communities. Hence, this study investigates a super-regional alliance of tourism and leisure suppliers as well as its effects on the community in the region of Tyrol, Austria. In the framework of 60 guided interviews, all organizations engaged in the Leisure Card Tirol (LCT) were contacted and questioned. The analysis of the qualitative data shows the motives for joining the alliance are either economic or non-economic in nature, and thus the alliance is evaluated differently by the various suppliers. Several corporations including swimming pools, ice skating rinks, museums, a football stadium (limited access), and mountain railway companies attract more locals to consume leisure (a partly merit good) due to their membership in the LCT alliance. However, the suppliers' heterogeneity in respect of their management (governmental, private, and mixed forms) is suggested to be the reason behind the LCT's financial survival. In summary, intentional coopetition in the context of a super-regional year-around pass may be a sustainable model of increasing a local community's welfare by providing affordable leisure activities, although some minor and major issues on the part of the suppliers might occur.
\end{abstract}

Keywords: coopetition; leisure card; supplier; welfare; local community

\section{Introduction}

Tourist cards are well-known and often-used ways of bundling visitor attractions in tourist destinations, offering mainly a combination of museum entries, means of transport, and/or other services for tourists at reasonable prices. In this context, Steinbach [1] defines tourist cards as territorial offers which contribute to the increased promotion of local and regional tourism products by combining various services and providing certain discounts in order to generate additional demand at the destination [2]. A similar idea in terms of a season pass for sport and/or leisure facilities (e.g., swimming pools, ski resorts) is offered by local suppliers in order to attract the local community to use those facilities by saving money due to frequent use compared to a single visit of the infrastructure. In turn, such leisure cards are predominantly schemes in the context of social marketing provided in order to increase the welfare of the target audience. This manifests itself mainly in the form of health, social, and partly educational benefits. As a general rule, cards like these tend to focus on rather deprived parts of the community due to their governmental management, and thereby occupy another alignment than regular tourist cards. Research shows existing leisure cards lack several essential points [3]. On the one hand, there seems to be a clear underinvestment in the management; on the 
other hand, there are too few schemes including alliances of both private and public companies. Such card schemes would also need professional marketing.

This paper analyzes a specific leisure card combining several offers for community members in a sport-culture-leisure-tourism-community context in Tyrol, a province in Western Austria. The Leisure Card Tirol (LCT) is a modified tourism concept (tourist card) embedded in a local community and therefore similar to, but at the same time distinctive from, traditional leisure cards. Thus, prima facie, the LCT faces the earlier mentioned challenges [3]; but, indeed, it is under private management. Therefore, it supposedly pursues an aim other than just local welfare. Assumingly, the LCT's prime motives deviate from those of conventional leisure cards and appear to be closer to the ones of tourist card suppliers. In this context, Borchert [4] states "the main target outcome of the introduction of destination cards in the last couple of years is the generation of additional demand" (p. 76), and often these destination cards are a tool of destination marketing organizations (DMO). One example is the Italian region Basilicata, offering a tourist card with several discounts for services and products and thereby providing a practical and flexible tool with the ability of making the stay more comfortable [5]. A similar card is sold by a DMO in Switzerland: it has an embedded chip which allows its holders to access a series of attractions within the canton [6]. In summary, research regarding those tourist cards-also referred to as "destination cards", "city cards", "city passes", "tourist passes", "guest cards", "welcome cards", or "visitor cards" [5]—has received certain attention: various studies have investigated the phenomenon of destination cards from different perspectives (e.g., [7-10]). Contrary to this, specific leisure cards such as the LCT, which constitutes a mixture of leisure card (residential orientation) and tourist card (economic orientation), combining a wide range of sport, culture, leisure, and tourism offers, have not yet been analyzed within a scholarly context. For this reason and with regard to the commercial focus of the LCT, investigating the card from the suppliers' view seems promising.

The members of the LCT alliance distinctly differ in size, industrial sector, and their form of management (governmental, private, or mixed). Thus, the LCT is an alliance of heterogeneous suppliers in leisure industries who compete against each other. At the same time, they collaborate and create a holistic leisure experience in Tyrol. Hence, the term "coopetition" can be used to describe this phenomenon. The co-occurrence of cooperation and competition has found high general approval in other contexts in recent years. However, with the exception of some scholars, only minor attention has been paid to relationships between medium-sized and small corporations in contexts that exclude key players [11] — a condition that applies for the LCT. Moreover, according to the review of Dorn, Schweiger, and Albers [11], only a few scholars have examined the possible advantage of coopetitive alliances arising from the cultural similarity of its actors [12]. We argue that the LCT alliance's members are culturally similar as they operate within one region, namely Tyrol. Finally, we assume the suppliers' participation in the LCT alliance to be rather exploitative and less explorative- $a$ form of coopetition/relationship that is characterized by routinization, control, and coupled systems [13] and has experienced little attention so far [11].

Considering these research gaps, the present study based on the case study of the LCT and the view of its suppliers aims to give answers to the following three research questions:

(1) What are the motives of suppliers for joining an alliance such as the LCT, and how is the concept of coopetition applied?

(2) What are the effects of participating in a coopetition such as the LCT alliance-for the suppliers as well as for the community?

(3) How satisfied are the suppliers acting in an alliance such as the LCT, and what can others learn from this experience?

The paper at hand is structured as follows: the next chapter (1.1) presents the theoretical and analytical framework, before the method (Section 2) and results (Section 3) sections follow. After discussing the data (Section 4), the authors derive implications (Section 5), both for destination marketing and for future research. 


\subsection{Literature Review and Analytical Framework}

\subsubsection{Coopetition and Motives for Coopetition}

The coopetition paradigm postulates that corporations not only compete against or cooperate with each other, but do both at the same time [14,15]. Until the late 1980s, coopetition was predominantly classified as a mechanism for the purpose of price discrimination [16,17]. However, its acceptance among policymakers in the USA, Asia, and the EU has increased [18,19] over the last years. In terms of an economic evaluation, "the extant literature provides a rich but thus far inconclusive account of how coopetition affects firm performance" (p. 307) [8]. On the one hand, there is some evidence that coopetition is an unsafe relationship, which often ends up in a debacle [20]; on the other hand, some studies postulate it may be beneficial for market performance [21]. In turn, Hamel argues a detrimental "learning race" might occur [22], and Kim and Parkhe postulate coopetition may be detrimental to alliance performance [23]. Considering these studies, it can be concluded that the success of a company in a coopetition does not only depend on the specificities of the company and the alliance, but also on the economic and industrial context in which it is implemented [24]. In this connection, there are different numbers of studies regarding coopetition in various industrial sectors. For example, coopetition was comprehensively investigated in the fields of ICT consulting [25], healthcare [26], or the food industry [27]. However, according to the extensive review of Bouncken, Gast, Kraus, and Bogers [28], there is no study dealing with leisure cards in particular. Regarding tourism, the body of literature - investigating forms of coopetition in the field of destination marketing — can be considered satisfactory [29-32]; nevertheless, the topic seems to be underexploited according to Chim-Miki [33]. Thus, the study in hand takes the most relevant of those studies into account, even though the product LCT can be purchased only by residents and hence cannot be seen as "touristic" in its nature. Furthermore, the present paper uses the term "strategic alliance" to describe the network of the LCT suppliers. Two paradigms hold true for this case: on the one hand, "a strategic alliance is sometimes equated with a joint venture, but an alliance may involve competitors" (p. 39); on the other hand, "strategic alliances are agreements between companies that remain independent and are often in competition" (p. 40) [34].

Overall, research regarding coopetition relies on various theoretical perspectives. From an economic point of view, institutional economics [35], the transaction cost theory [20,36], game theory [15,18,37,38], the resource-based view [39-43], a network approach [44], and the dynamic capabilities theory [45] find usage. In the context of game theory, Brandenburger and Nalebuff [15] argue that coopetition incorporates the logic that companies initially work together for the purpose of increasing their market share conjointly, before they finally start a competition to split it up. Considering this assumption, one may conclude that coopetitive alliances are promising if the coopetitive partners are reciprocally able to extend the overall value compared to the value they could otherwise capture on their own. Therefore, competitors build a network in order to create advantages for all members of the network [46]. Furthermore, the mentioned added value may result from pooling resources, fending off rivals, and the exchange of ideas, according to Lado, Boyd, and Hanlon [42].

Regarding the motives for joining a coopetitive alliance, Bengtsson and Kock [47] summarize the main intention with the following words: "the obvious reason is that the relationship is advantageous" (p. 424). In his study on coopetitive strategies, Ritala [24] splits the motives firms have for participating in a coopetition into three parts. Firstly, he argues that "increasing the size of the current market or creating totally new ones is among the most obvious motives" (p. 309). Radical and incremental innovations, respectively, count as examples for such issues [43,48,49]. In this connection, participants are able to offer added value for their end consumers within the framework of an enhanced and collaborative basis [35,50,51]. Secondly, "firms may wish to use fewer resources, or to use their current resources more efficiently, in serving their existing share of the market" (p. 309) [8]. Accordingly, Dussauge, Garrette, and Mitchell [24] postulate this motive is well reflected within the context of scale alliances [52]. Thirdly, suppliers may want to " (...) protect the share of the market they have been able to capture and to conquer a 
larger share of what remains" (p. 309). In other words, firms choose a coopetitive strategy in order to maintain their position and interests respectively, to co-opt their rivals, and to go with technological innovations $[18,53,54]$. All in all, it has been suggested that coopetition may be either a positive-, negative-, or zero-sum game for its participants, and furthermore, it depends on both the alliance members' economic alignment and the economic environment that determines the output [55].

As the study in hand aims at expanding the existing literature by providing a concrete case study, we will try to capture the phenomenon from an externally-viewed perspective, examining a functioning coopetitive alliance in its entire width, and thus, renounce precise economical figures. Therefore, the motives of members participating in the LCT alliance will be visualized in a first step.

\subsubsection{Effects of the Coopetition and Evaluation}

Aside from the motives for joining the LCT, a coopetitive alliance has several effects. Firstly, coopetition may be beneficial in terms of both market performance and innovation performance [24]. Regarding the overall firm performance, Kim and Parkhe [23] as well as Park and Russo [20] postulate rather negative outcomes for coopetition, Knudsen [56] holds a neutral opinion, whereas several other studies indicate rather positive outcomes: Quintana-García and Benavides-Velasco [43] showed that coopetition may increase the technological diversity as well as the development of new products by taking a European biotechnology corporation as an example. Belderbos [48] postulated a positive effect on both sales per employee and labor productivity in innovating Dutch corporations. Furthermore, Robert et al. [57] argue that coopetition influences the economic performance of French football clubs positively, but does not have an impact on their sporting results. Summarizing, a solid number of studies in various sectors conducted in different manners prove that coopetition has the potential to provide positive effects [21,58-61]. Special attention needs to be paid to a study which is relatively similar to ours, at least in terms of the supplier composition: Lorgnier and CheJen [62] found enhanced financial performance in a sport-tourism-network of seven non-profit, one for-profit, and three public corporations situated in a coastal area in northern France.

Considering these mainly positive but still diverging results, we will gather information about the way in and the extent to which the participants of the alliance experience effects in connection with the coopetition. Nevertheless, our interest is not focused on an in-depth economic analysis, but rather targets the suppliers' perception of potential effects. In this context, Bouncken et al. [28] provide a systematic review of the term coopetition and list a variety of studies covering both risky and potentially beneficial effects.

In addition to the above-mentioned outcomes, the findings of Bouncken et al. [28] suggest industrial and environmental contexts; thereby, externalities, certainty, competitiveness, etc. have been taken into account. Since the LCT alliance members differ in their legal forms-both private and governmental firms can be found-our approach will also have to deal with the issue of cross-sector relationships between for-profit and non-profit suppliers; a challenging situation [62]. In the sports service sector, challenges may result from the fear of increased prices on the part of the non-profit suppliers, from goal incongruity [63], and also from the lack of shared visions and values, respectively [64]. Finally, Bouncken et al. state that "only 17 of 82 studies have worked with quantitative methods [which] demonstrates that coopetition research is still in its infancy" (p. 591) [17]; but, at the same time, there is a lack of research regarding small and medium-sized enterprises (SMEs) and industries which are neither knowledge-intensive, nor dynamic, nor complex. Indeed, only a limited number of studies have focused on SMEs — a firm size predominantly represented in the LCT—even though coopetition may promote benefits for those enterprises $[57,58,65,66]$. In view of these statements, this study will include the legal forms of the participating corporations when it comes to analyzing the coopetition effects, but also consider SME-specific literature. Overall, we aim at providing a comprehensive case study of a constantly growing leisure alliance. 


\subsubsection{Evaluation of the Coopetition}

As elucidated, the study wants to illustrate the participants' motives to join the alliance in a first step, followed by an analysis of the occurring effects, and finally, by the evaluation of these effects as seen from a supplier's perspective. Regarding the last-mentioned aspect, it is obviously necessary to act in a friendly manner within the cooperative part of the coopetition to experience successful coopetition [47]. Moreover, active management is required in such alliances to decide "what to share, with whom, when, and under which conditions" (p. 642) [65]. Furthermore, as elucidated in Chapters 1.1.2 and 1.1.3, heterogeneity among the participants (especially a cross-sector relationship) comes with issues, but also changes the manner of evaluating the outcomes. In this sense and with regard to the qualitative character of the approach, it seems promising to extend the motives as well as the outcomes of the coopetition by a supplier-specific evaluation. Moreover, this approach will help to close the research gap: the interplay between non-profit, for-profit, and public organizations has rarely been studied in this connection [67,68], though the study of Kylänen and Rusko [69] makes a comparable exception.

Thus, considering the extant literature, our proposed analytical framework is based on three phases, identifying the elementary context, the effects of the LCT, and the evaluation of the output as shown in Figure 1. First of all, a network needs to be created (Phase 1) out of private (Corp. P), mixed (Corp. P/G), and throughout governmental corporations (Corp. G) in order to provide an attractive product (Phase 2). This should lead to outputs such as revenue and/or customer value creation (Phase 3). Both the results and discussion sections will refer to this framework. It should be noted that the coopetition illustrated in Figure 1 refers to residents as its resource (target-group): the LCT suppliers cooperate to create added value by selling their common product, the LCT, to residents and then compete for jointly generated revenue. Another kind of coopetition within the LCT alliance is the combination of competition in terms of tourists and cooperation in terms of residents (common leisure card); however, this aspect is not presented in the following framework.

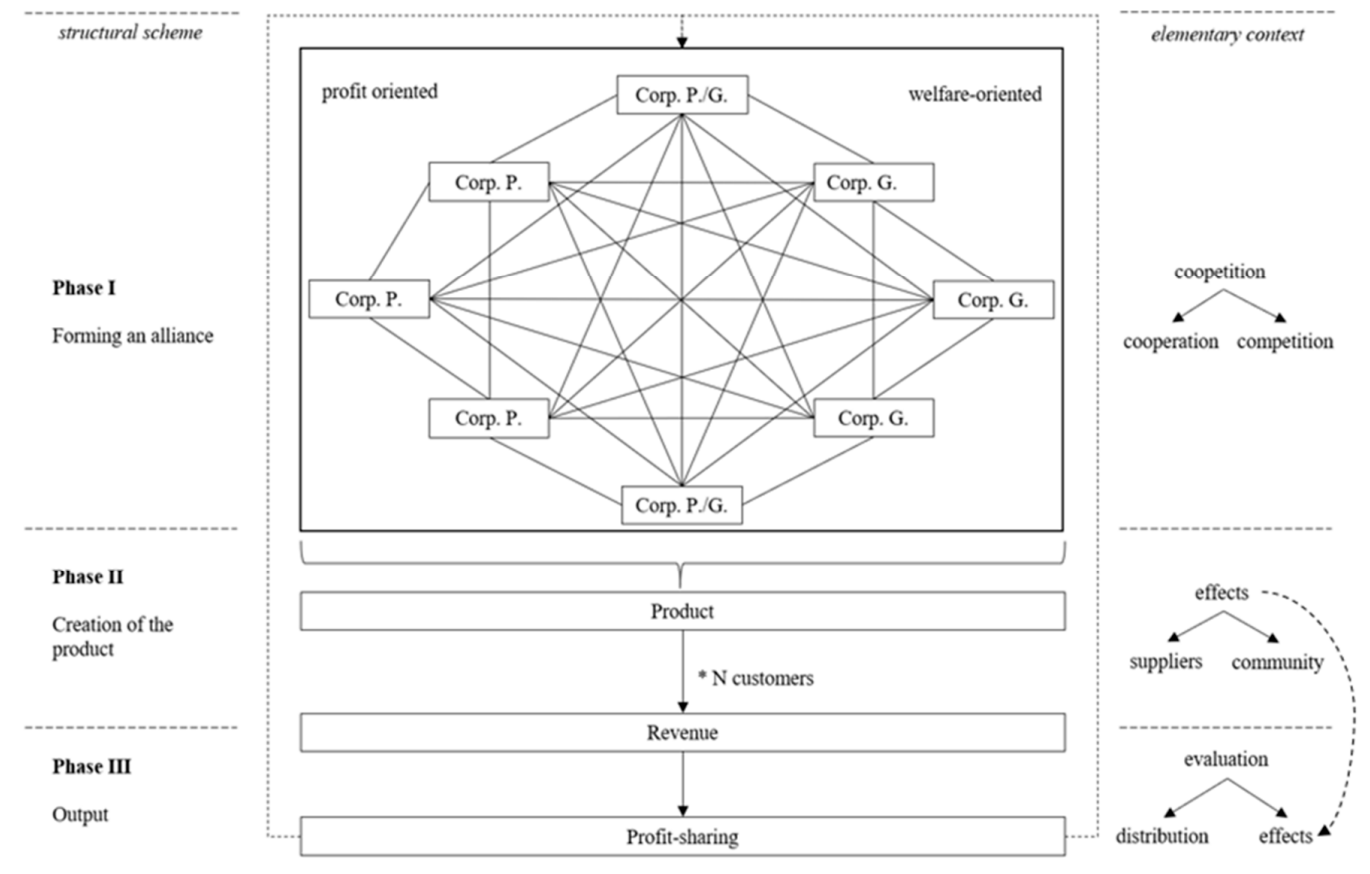

Figure 1. The analytical framework behind the Leisure Card Tirol (LCT).

The LCT has existed in the region of Tyrol since 2005 and offers access to various leisure attractions. In 2017, the LCT was sold to about 54,000 ticket holders (1/6 of the population of Innsbruck and its 
surroundings). The LCT provides access to several local ski resorts, swimming pools (indoor and outdoor), ice skating rinks, and museums. Furthermore, it offers discounts with certain bonus partners such as leisure and sports equipment suppliers or the option to visit soccer matches of the local team for free (limited number of visits). The LCT is valid for one year. The regular price (2017/18) is $€ 512$ for adults and $€ 256$ for children under 14, whereas various discounts are given e.g., pre-sale, youth, seniors, or family tickets: if one parent purchases the LCT, children under 14 pay $€ 68$ (pre-sale: $€ 63)$ and children under 6 are free. In comparison with the standard prices for season passes in various ski resorts, the LCT is decisively cheaper, especially given its comprehensive application area. The management of the LCT is located in Innsbruck and representatively managed by one of the suppliers, the Innsbrucker Nordkettenbahnen (MR6), who periodically organizes meetings for all participants. Within these regular discussions, the prices of the card as well as the distribution of income are reviewed. At the time of the interviews, only the big mountain railway corporations within the alliance get payments depending on the number of visits-all the other suppliers (including the smaller mountain railways) receive a fixed amount. The LCT is comparable to other strategic alliances—which are widely examined (e.g., [53,70,71]) — as it is based on a written contract stipulating the distribution of income and further regulations.

\section{Materials and Methods}

In order to give answers to the research questions, 60 guided interviews (mountain railway companies $(N=23)$, swimming pools $(N=12)$, bonus partners $(N=13)$, museums $(N=6)$, and ice skating rinks $(N=6))$ were conducted. The study at hand uses qualitative methods; this procedure shall allow further insights into the perceived values of this kind of coopetition project. Due to the manageable number of suppliers, no sample had to be taken, but all of the suppliers were contacted in agreement with the LCT's general management. Interviews with the respective contact persons of the suppliers-mainly the managers-were conducted between 3 May, and 19 July 2016. The interviews lasted 15 to $60 \mathrm{~min}$; more details are provided in Table 1.

Table 1. Information on the interviews with the LCT alliance participants.

\begin{tabular}{ccccc}
\hline Mountain Railways $(\boldsymbol{N}=\mathbf{2 3})$ & $\begin{array}{c}\text { Interview Length } \\
\text { (min) }\end{array}$ & Shareholder(s) & Season & Acronym \\
\hline 11er-Lifte Stubai & 28 & Mixed & All & MR1 \\
Axamer Lizum & 35 & Mixed & All & MR2 \\
Bergbahnen Kappl & 20 & Government & All & MR3 \\
Bergbahnen Rosshütte & 75 & Government & All & MR4 \\
Bergbahn Silvretta Galtür & 25 & Mixed & All & MR5 \\
Innsbrucker Nordkettenbahnen & 25 & Mixed & All & MR6 \\
Kellerjoch & 20 & Private & All & MR7 \\
Kühtai & 15 & Mixed & All & MR8 \\
Muttereralm-Bergbahnen & 20 & Government & All & MR9 \\
Patscherkofelbahnen Igls & 30 & Government & All & MR10 \\
Rangger Köpfl & 10 & Government & Winter & MR11 \\
Skilift Kinderland Rinn & 50 & Government & Winter & MR12 \\
Schwannerlift & 21 & Private & Winter & MR13 \\
Serlesbahn Mieders & 10 & Government & All & MR14 \\
Silvrettaseilbahn AG Ischgl & 10 & Private & All & MR15 \\
Ski - \& Freizeitarena Bergeralm & 15 & Private & All & MR16 \\
Ski Arlberg & 15 & Private & All & MR17 \\
Skilift Trins & 20 & Government & Winter & MR18 \\
Skiregion Obergurgl-Hochgurgl & 45 & Private & All & MR19 \\
Sonnenberglift Gries & 20 & Private & Winter & MR20 \\
Stubaier Gletscher & 15 & Private & All & MR21 \\
Unterberghornbahn & 20 & Private & All & MR22 \\
Wildstättlift Wattenberg & 25 & Government & Winter & MR23 \\
\hline & & & & \\
\hline & & & & \\
& & & &
\end{tabular}


Table 1. Cont.

\begin{tabular}{|c|c|c|c|c|}
\hline Swimming Pools $(N=12)$ & $\begin{array}{l}\text { Interview Length } \\
\text { (min) }\end{array}$ & Shareholder(s) & Season & Acronym \\
\hline Hall AG & 35 & Government & Sommer & SP1 \\
\hline Innsbrucker Kommunalbetriebe & 30 & Government & All & SP2 \\
\hline Freizeitzentrum Neustift & 20 & Government & All & SP3 \\
\hline Freizeitzentrum Axams & 25 & Government & All & SP4 \\
\hline Ferienparadies Natterersee & 26 & Private & Summer & SP5 \\
\hline Strandperle Seefeld & 20 & Private & Summer & SP6 \\
\hline Erlebnisbad Schwaz & 15 & Government & Summer & SP7 \\
\hline Schwimmbad Inzing & 20 & Government & Summer & SP8 \\
\hline Schwimmbad Mieders & 15 & Government & Summer & SP9 \\
\hline Familienbad Mutters & 15 & Government & Summer & SP10 \\
\hline Freibad Wattens & 20 & Government & Summer & SP11 \\
\hline Badeanlage Zirl & 12 & Government & Summer & SP12 \\
\hline Ice Skating Rinks $(N=6)$ & $\begin{array}{l}\text { Interview Length } \\
\text { (min) }\end{array}$ & Shareholder(s) & Season & Acronym \\
\hline Eislaufplatz Götzens & 10 & Government & Winter & ISR1 \\
\hline Eislaufplatz Schwaz & 15 & Government & Winter & ISR2 \\
\hline Eislaufplatz Zirl & 12 & Government & Winter & ISR3 \\
\hline $\begin{array}{l}\text { Eislaufplat Baggersee, } \\
\text { Hötting-West, Sparkassenplatz }\end{array}$ & 15 & Government & All & ISR4 \\
\hline Wasserkraftarena Innsbruck & 20 & Government & Winter & ISR5 \\
\hline Eislaufplatz Wattens & 10 & Government & Winter & ISR6 \\
\hline \multicolumn{5}{|l|}{ Bonus Partners $(N=13)$} \\
\hline Air 4 You Tandemflüge & 25 & Private & All & BP1 \\
\hline Appelt Juwelen & 15 & Private & All & $\mathrm{BP} 2$ \\
\hline Blue Tomato Shop Innsbruck & 10 & Private & All & $\mathrm{BP} 3$ \\
\hline Body \& Soul & 30 & Private & All & $\mathrm{BP} 4$ \\
\hline FC Wacker Innsbruck & 25 & Mixed & All & BP5 \\
\hline Ferdinand Purner Lichtspiele & 10 & Private & All & BP6 \\
\hline Golfacademy Seefeld Reith & 10 & Private & Summer & BP7 \\
\hline Intersport KHT & 25 & Private & All & BP8 \\
\hline Intersport Pittl & 15 & Private & All & BP9 \\
\hline Mountain Soaring & 25 & Private & All & BP10 \\
\hline Oakley Store Innsbruck & 30 & Private & All & BP11 \\
\hline OutdoorCircuit Innsbruck & 15 & Private & All & BP12 \\
\hline Tobias Alexander Meier & 25 & Private & All & BP13 \\
\hline \multicolumn{5}{|l|}{ Museums $(N=6)$} \\
\hline Audioversum Innsbruck & 25 & Private & All & MU1 \\
\hline Glockengießerei Grassmayr & 20 & Private & All & MU2 \\
\hline Museum der Völker & 20 & NPO & All & MU3 \\
\hline $\begin{array}{c}\text { Stadtmuseum Innsbruck Museum } \\
\text { Goldenes Dachl }\end{array}$ & 30 & Government & All & MU4 \\
\hline Swarovski Kristallwelten & 25 & Private & All & MU5 \\
\hline Tiroler Landesmuseen & 25 & Government & All & MU6 \\
\hline
\end{tabular}

The main terms of reference firstly comprised general questions about the suppliers, and furthermore, about the motives for their LCT membership. Secondly, we asked about the effects which occured due to their participation. In this context, the main focus was laid on a possible marketing (advertising) effect, a possible visitor effect, and a possible (financial) impact on the market performance. In the following, the term "increase in visitors" stands for an increase in the number of different visitors and "increase in visits" just means more visits in total (including multiple visits by a single individual). Thirdly, the emphasis was put on the suppliers' evaluation of the resulting effects and their overall contentment, especially in regard to the distribution of income. 
The raw material was read and encoded following the qualitative content analysis of Fenzl and Mayring [72]. Quotes, themes, and paraphrased quotes were identified individually when they seemed to be a considerable point or thought. Moreover, a typology of the participating corporations was compiled, including their legal forms and further key results.

\section{Results}

The results can be split into three parts, as Figure 1 suggests. The first part describes the backgrounds which led to the increase in LCT suppliers, focusing on coopetition. The second part will show the effects caused by the coopetition, and eventually, the interviewees' personal opinions about the card will be illustrated in the third part of the study (evaluation).

\subsection{Coopetition and Motives for Coopetition}

The closer examination of the motives for joining the LCT coopetition revealed that "seeking for more customers" was the prime motivation for becoming part of the alliance. Irrespectively of their legal form, most companies expected a higher number of visitors and visits, respectively as a result of their membership.

- We have heard very positive references about the LCT. There are several people who work in the museum field and already participate in the project. Furthermore, I also know swimming pool owners who warmly recommend the ticket. In my opinion, it helps in attracting new customers. This is actually the main reason. (MU1)

- $\quad$ Getting additional customers and increasing first-time visits, extending the offer for Tiroleans. (MR3)

- $\quad$ The Elfer is a very small skiing area. Therefore, participating in the LCT project is very inviting and interesting for us. People who would normally visit bigger skiing areas visit the Elfer because they have already purchased the ticket and think "today I will go there". (MR1)

- We wanted to increase the number of visitors and visits. I also want to mention that residents seldom appreciate the surroundings and the attractions that their area has to offer. Even the Tiroleans, who are well known for being tourism champions, spend their holidays far away and visit museums abroad, but seldom at home. Let us consider the Eiffel tower as an example: most tourists go to Paris to see and visit it, but just a few Parisians have already done that. It happens everywhere in the world. (MU2)

Aside from seeking for more customers, there were several other economic motives. On the one hand, some corporations, especially small ones, were forced to join the LCT alliance due to a lack of visitors; on the other hand, some bigger suppliers attempted to benefit from scale effects.

- $\quad$ The number of visitors to our bathing area had dropped dramatically since the introduction of the leisure ticket, because people who purchased the leisure ticket visited businesses that were partners already. This had made a noticeable difference in what concerns the number of visitors. This is why we have joined the LCT network. (SP5)

- $\quad$ Our skiing area has a transport capacity of 4300 people per hour, and our hotels have 5000 beds available. This means that we have an overcapacity and thus a lot of space for day guests. Day visitors need a motivating factor to drive to Gurgl, which can be achieved only by establishing discounted tariffs or creating a combined ticket like the LCT. (MR19)

However, a few corporations stated that non-economic motives (political power or residents exerting pressure to take part) were crucial for them to enter the LCT alliance. Either political power or the attempt to increase the locals' welfare made those companies-mainly, but not exclusively governmental corporations-join.

- $\quad$ Actually, we did not think about it in depth. We act as partners of the LCT because of political will. (MR15)

- The main consideration is a political one. The city of Innsbruck wanted to give families and children a chance to visit the public swimming pools at a reasonable price. (SP2) 
- As a municipality, we are primarily responsible for our citizens, and we want to create good offers for them. Our main goal is that sport and leisure activities, especially those for children and teenagers, remain affordable and as multifaceted as possible. It is very important to us that many people do sports. This improves their health and enhances their sense of togetherness. Therefore, these offers, which represent a good supplement, are very important to us. (SP7, ISR2)

- $\quad$ The citizens of Wattenberg wanted to become part of the leisure ticket because it enables them to use other mountain railways as well as our ski lift. (MR23)

\subsection{Effects}

The effects show huge diversity among our findings. First of all, most of the corporations, the large mountain railway corporations included, attribute a positive marketing effect to the LCT.

- Definitely. We also want to focus on families with promotions in magazines or reading circles. The grandstand for families and the LCT grandstand are in the same place. This is much more attractive for families with children. (BP5)

- Yes, of course. They [LCT management] are very present and have clear logo guidelines. We have the logo on our website, too. (MR13)

- For a small business like ours the LCT is a great opportunity, because we only have a very limited budget for marketing at our disposal. Being a part of it is definitely positive. (MR12)

- We obviously did not profit from it [in terms of marketing]. (SP1)

Moreover, several small and medium-sized corporations experience an increased number of visitors and/or visits, while the major ones could not report a noticeable effect. Overall, none of the suppliers stated they would experience fewer customers than before their membership in the LCT alliance.

- We have noticed many immediate effects such as increased visitor numbers and new guests. We are not talking about regular visitors here: the number of new guests is increasing, and they are simply looking for places where they can go for free. Whether they return depends on us, and actually, they visit us over and over again. (SP6)

- $\quad$ There are no disadvantages. If an LCT holder comes to us, we can be pretty sure that he would not visit the museum without it. (MU4)

- Yes, it [number of visits] has definitely increased. (MR12)

- $\quad$ The number of visitors has changed positively. Thanks to the LCT, the customer visits the ski area for a shorter time, especially in winter. The customer often comes spontaneously for two hours only, even if the weather or the slopes are not so good. This would not happen without the LCT, and due to this fact, the number of entries have developed positively. (MR9)

- $\quad$ The number of visitors has not changed much. Visitors who used to have our own season pass opted for the LCT, though. (MR7)

Furthermore, the market performance of the major suppliers is relatively unaffected by the LCT. In contrast to this, some isolated positive as well as a few negative influences for smaller and medium-sized suppliers have to be stated.

- We always get the same amount, it does not make a difference whether we have one or 10,000 visitors. This has had a negative economic impact on us. We get a lump sum, but people do not buy day tickets anymore, because they all prefer to purchase the LCT. (MR12)

- $\quad$ The customer frequency has positively increased, but there is almost no connection with the overall business success. (MU5)

- $\quad$ As I said before, the profits earned with our own season passes have decreased. When we have a great season and nice weather, the LCT has a clearly negative impact, because we could have sold more tickets. Three 
years ago, the season was terribly rainy: in that case, we were glad that we could count on this income and on the lump sum. To sum up: we have the same number of visitors, but we lose more money due to the noticeably decreasing number of regular tickets we sell. (SP1)

- Yes, the LCT enhances our business success. (MR6)

\subsection{Evaluation}

The distribution of income is predominantly well-accepted, even though all suppliers other than the big mountain railway companies have to be satisfied with bilateral conventions. Only isolated grievances occur: some smaller companies complained about the calculation of the profit distribution, mainly due to their fixed profit-sharing.

- It could always be more. When I have a look at my list: 30 per cent of the entries, but only 12 per cent of the sales. Our wish is to get more money. (SP8)

- We are a very small skiing area with no access system, and for this reason we get paid with a lump sum. This is a bad deal for us, because we had more entries and get a relatively small compensation; the lump sum we get is too low. It was higher in the beginning and we could not report many entries during the first two years. The lump sum was reduced then and now it is not worth the effort. (MR13)

- Yes, we [the LCT] are clearly too cheap, especially compared to other combined passes! Why? Because the performance of the LCT is enormous, compared to its price. (MR2)

- We do not have any objections. (MR7)

In summary, it can be said the prior elucidated motives for a company's LCT membership and the results basically coincide. The answers regarding the issue "fulfilment of expectations towards the LCT" turned out to be mostly positive.

- We wanted to make the locals happy and we were able to do it. It did not pay off from a commercial point of view, but our citizens are satisfied. (MR23)

- Yes, we simply expected a good customer stream and it is definitely here-we have it - it has come. (BP3)

- $\quad$ Our expectations were fully fulfilled. (MR4)

- $\quad$ No [answering the question of whether they are satisfied with the coopetition's effects]. (BP7)

The supplementary of this manuscript provides a summary of the key results.

\section{Discussion}

The product "leisure" can be seen as a merit good. The card provides access to several sporting (sports facilities) or educational (museums) leisure activities. The suppliers build a network that isolates themselves from non-participating corporations. In this sense, the statement of Lorgnier and CheJen [36] applies: "Coopetition is a neologism that defines a hybrid behavior of cooperation and of competition [15,73] within an organization [74] or between organizations [14], whose objective is added value [46]" (p. 89). The findings of the study at hand support this statement.

For a better overview, the remaining discussion is divided into three parts, just as with the results and the theory section: firstly, the motives for the coopetition; secondly, its effects; and finally, the evaluation of the coopetition on the part of the suppliers. Furthermore, it seems necessary to take the strength of the ties between the suppliers into account [62]. In general, researchers distinguish companies which are geographically and/or temporally separated, joined, or related [46] to evaluate the strength of the connection. In the context of the network theory, the linkage can be indicated as strong, moderate, or weak $[75,76]$, whereas "( . . ) these attributes remain undefined" (p. 93) [62] according to Lorgnier and CheJen. Independent of this, one could assume the linkages between the individual suppliers of LCT vary greatly. On the one hand, their resource is the same (residents), geographical narrowness exists, and a written contract comes along with the alliance; but, on the other hand, some of the suppliers are very diverse (from a small museum in Innsbruck to Austria's biggest 
skiing region) and therefore hardly direct competitors. Due to the sample size and the method of the approach, we are not able to give details about every linkage between the various suppliers, but we suggest keeping this aspect in mind during the further discussion.

\subsection{Coopetition and Motives of Coopetition}

One of the main purposes of the study was to examine the motives of why the interviewed organizations joined the LCT alliance. The general tendency shows a major part of the results coincide with the premise postulated in Section 1.1.3 which implicates that suppliers seek "improvement in the firm's competitive position through coopetitive alliances" (p. 309) [24].

As the findings suggest, the main focus of many corporations is to increase the number of visitors-in other words, most companies join for a better competitive position leading to more visitors. Both more visitors and more visits were named, but the main focus is laid on the visitors. Considering these statements, "( . . ) increasing the size of the current market or creating totally new ones is among the most obvious motives" (p. 309) [24]. In this connection, some suppliers state they attracted some new customers only due to the LCT. Moreover, several other economic motives were mentioned as motives for the membership: due to an economic calculus, one of the bigger skiing regions (i.e., MR19) intended to reduce its overcapacity by attracting more day guests. In that context, the paradigm that "firms may wish to use fewer resources, or to use their current resources more efficiently, in serving their existing share of the market" (p. 310) applies [24]. This motive is argued to be well represented in connection with scale alliances [52]. However, we could find only one supplier who named resource considerations to justify his membership. Another supplier revealed he was economically forced to join the alliance: due to a significant decrease in visitors-rivals who were already part of the coopetition suddenly attracted his visitors-he had no other option but to join the LCT. This goes in line with the assumption that suppliers may want to "( ... ) protect the share of the market they have been able to capture and to conquer a larger share of what remains" (p. 309), even if in a negative way [24]. In other words, the substitution effect in the local area is too far-reaching to deal with for suppliers who want to maintain their own position. In this regard, the premise "( ... ) that the relationship is advantageous" (p. 424) [47] is questionable for some suppliers. Our analysis confirms the statement of Bonel and Rocco [77], who argue that coopetition can either be the solution for a corporation's issues, but also the origin of another corporation's problem. Aside from these motives, further motives are comprehensively discussed in the extant literature [18,53,54]—for example, co-opting rivals or going with technological innovations-yet none of those were relevant to our findings.

However, several suppliers explained their membership with other than economic motives. In some cases, political backgrounds obviously made an extensive decision-making process redundant. Most of the governmental corporations joined the alliance in order to provide the merit good "leisure and sports" to a bigger part of the community. For example, one supplier indicated his membership was only due to the will of the local residents, which in this sense can be interpreted as a direct attempt to increase their welfare.

Another issue concerns the discussion of the motives: the suppliers evaluated whether they considered the LCT as a primarily competitive or primarily cooperative coopetitive alliance. Except for one supplier, the results suggest the LCT alliance is solely perceived as mainly cooperative. The same perception holds true within the goods industry in general $[47,78]$.

Overall, our findings regarding the motives for joining the coopetitive alliance can be summarized in line with the first part of the statement of Brandenburger and Nalebuff [15]. According to them, a predominant part of the suppliers intends to work cooperatively together to maximize the common creation of value. However, the term "value" should be viewed from a broader perspective. We suggest taking the legal form of the suppliers into account, when it comes to a discussion in this connection. While private participants predominantly seek better market performance-which in fact is their added value-governmental suppliers join the alliance in order to generate welfare, which does not necessarily show up in the balances. Hence, in which way and to which extent this coopetitive procedure actually 
works will be argued in the following part of the discussion. Moreover, the classification of the final distribution and its evaluation on the part of the suppliers will be conducted in this context.

\subsection{Effects}

Considering the variety of motives, the following discussion will take especially the shareholder situation into account. Regarding the effects of the coopetition in the study at hand, it can be postulated that both suppliers who joined the alliance due to economic motives and those who joined for non-economic motives experience very diverging outcomes. Moreover, we need to consider the suppliers' size - in fact, mainly small and medium firms-and respect their particularities, especially when it comes to benefits and risks [28]. Firstly, as the results suggest, nearly all of the suppliers attributed a marketing effect to the card. In general, this effect comes along with enhanced advertising for most of the suppliers. The LCT alliance is very present and well known among the local residents; in line with this, some suppliers mentioned the clear logo guidelines prescribed by the LCT management. Accordingly, some of the smaller suppliers reveal they would not have the possibilities to arrange a big marketing campaign on their own. In addition, the motive "seeking more customers" could be interpreted as an expression for a lack of market presence. Thus, this rather one-sidedly perceived effect coincides with the findings of Morris et al., stating that SMEs are usually limited in terms of resources and market presence [58]. Furthermore, Thomason et al. consider the issue as a reason for SMEs to participate in a coopetition [66]. In this context, Ritala and Hurmelinna-Laukkanen [36] as well as Stockdale and Williams [79] summarize the major effects of coopetition: economies of scale, sharing of know-how, improved financial performance, pooling of resources, and profit from complementary resources. Furthermore, Bengtsson et al. [80] postulate similar outcomes, namely increased competitiveness, access to needed resources, exploration of international opportunities, and finally, the development of technological innovations. Regarding the pooling of resources and profiting from complementary resources, the marketing effect provides a possibility for suppliers to benefit from those two factors. However, the extent to which economies of scale and improved financial performance respectively appear, will be argued at a later point in the discussion.

Aside from these findings, the second point-sharing of know-how-was not referred to in any of our interviews. This may be traced back to the fact that this point was not in particular asked for, in contrast to the specific questions on marketing and visitor effects. Overall, as elucidated prior, a marketing effect is prevalent; in other words, several suppliers attribute at least one effect to the LCT. Furthermore, and probably due to this first effect, the results clearly show that many suppliers experience more visits. The range of our results in this connection is remarkable, but first of all, no one experiences less visits. A detail of interest is shown by a supplie, who claimed he was forced to join the alliance due to dropping numbers of visits resulting from not being part of the coopetition. However, it is argued that the increase in visitors/visits results from new visitors but also from a higher frequency, which could be explained by the phenomenon of sunk costs [81]. Nevertheless, some suppliers did not experience any increase at all, as prior season pass holders simply became LCT holders.

As a whole, the coopetition within the LCT leads to more visitors/visits, which confirms the statements of Kylänen and Mariani [32] who claim that the coopetition among theme park suppliers may result in such an increase. Thus, the efficiency in resource utilization seems to be enhanced. The frequency of use is primarily interesting since most of the offers are related to sporting and educational facilities. Moreover, coopetition has rarely been studied on a collective level but rather on an individual level [82]. Hence, one could interpret the LCT as an enhanced and collaborating platform which offers added value for their end consumers $[35,50,51]$ in the context of an affordable and comprehensive access to the mentioned facilities.

Considering the increase in visitors/visits, the resulting market performance needs to be taken into account. With respect to the above-mentioned improved financial performance [36,79], Levy et al. also associate coopetition with increased financial performance for SMEs [65]. Furthermore, Oum et al. [83] 
succeeded in showing that horizontal alliances-we assume the LCT alliance is horizontal in its nature-have a positive impact on the suppliers' productivity but no effect on the profitability. Moreover, another study argues that the increase in customer satisfaction and customers' loyalty can enhance the profitability in the long-term on the basis of a coopetition strategy [84].

Considering the findings of the above-mentioned literature, our results are partly ambivalent. On the one hand, some smaller suppliers indicated they had to deal with negative economic impacts. Regarding this, Dowling et al. [85] noticed that especially competitive partnerships expose their members to problems in terms of the individual economic health. On the other hand, some suppliers stated the LCT increased their business success, going along with other studies $[57,74]$ and the above-mentioned study of Lorgnier and CheJen [61]. In the middle of those two extremes, there are several suppliers who did not experience any change in terms of market performance, even though some reported more visits. However, these assumptions must be precisely examined due to the prevalence of several motives and does not apply overall. In this context, the impact of the increase in visitors should be viewed in relation to the suppliers' size. The major skiing resorts within the LCT alliance did not experience a substantial increase in visitors, and as a result, experienced almost no financial effect. In other words, the importance of the card is marginal to them-especially due to the limited access they provide (three visits per year for each LCT card holder). Furthermore, some skiing regions claim they made a certain turnover in line with the LCT with their costs stagnating at the same time. This circumstance could be interpreted as a sort of positive scale effect. In fact, economies of scale are considered as one of the major effects of coopetition [36,79]. In contrast to that, some smaller LCT participants reported decreasing outputs of scale: aside from the firms' sizes, the discrepancy between suppliers who get paid fixed rates and suppliers whose share is calculated depending on the counted visits needs to be recognized in this context. Irrespective of the numbers of visitors, the first-mentioned suppliers always receive the same amount of money—both in a bad and in a good season. This leads to a certain degree of financial protection in bad seasons; but during good seasons those suppliers lose money with an increasing number of visitors from a certain point. Considering these two options, Morris et al. [58] postulate that, with regard to "bad seasons", coopetition can be seen as a risk management strategy in the context of lowering the uncertainty and costs, respectively. A risk management strategy could not be found by our study, but a mitigated financial uncertainty partly applies. Furthermore, the extent to which the coopetitive alliance is crucial for some suppliers needs to be questioned, as Gnyawali and Park [86] notice. Moreover, the findings of the study in hand conform with the results of Horch [87] as well as Stockdale and Williams [79], who state that non-profit organizations tend to occupy weaker positions when stronger linkage appears. Otherwise, one could assume that the drastic financial disadvantages among some LCT participants could lead to the end of the present alliance-if all of them insisted on getting paid according to the number of counted visits. Overall, the fact that suppliers within the LCT network are partly profit-oriented and partly welfare-oriented is probably decisive to enabling the economic stability of the coopetition.

According to Lorgnier and CheJen [62], coopetitors develop enhanced employability; hence, they encourage the locally coordinated implementation of strategies as a result of the coopetition. However, it can be assumed that such effects tend to play a secondary role within the LCT. Also, further far-reaching effects-for example, enhanced innovation capability as presented by Quintana-García and Benavides-Velasco [43] — could not be observed. Overall, our findings show that market performance benefits are lower than the increases in visitors might suggest. In addition to problems concerning the distribution of income, high network externalities may be beneficial for a coopetitive alliance [24]; however, this can be excluded in the context of the LCT, as almost all eligible firms are already part of the local alliance. Moreover, coopetition strategies may be conducive for the market performance in a highly uncertain market [24]. The leisure market in Tirol is assumed to be stable, but some suppliers still benefit from a certain level of financial protection in bad seasons. Finally, in the context of a low competition intensity, coopetition may be beneficial also for the market performance of the suppliers [24]. Competition intensity among the suppliers in the LCT network is supposed to show 
huge diversity. However, we argue that the financial performance within the LCT network is relatively independent of external factors and rather depends on the overall distribution of income.

The LCT alliance is remarkably heterogeneous, both in terms of suppliers and in terms of their experienced effects. Moreover, participating in the LCT network has only marginal effects on some of the suppliers-especially on restricted members (where the card allows only three visits a year). This heterogeneity may be responsible for the low competition within the coopetition. At the same time, the LCT alliance seems to be a form of cooperation-dominant coopetition [14]. In summary, our results confirm the statement of Pellegrin-Boucher, Le Roy, and Gurau [88] who argue that coopetitive strategies should be considered as both, a source of additional risk and a source of possibly enhanced performance.

\subsection{Evaluation}

Finally, we examined the extent to which the suppliers are satisfied with the LCT. Regarding the evaluation of the above-discussed effects and the distribution of income, we again see widely diverging opinions. The evaluation of the income distribution obviously depends on the specific market performance. None of the suppliers who are paid depending on the counted visits indicated dissatisfaction in this context. On the contrary, some suppliers who experience a financial loss were explicitly not satisfied with their lump sum, whereas some of them still were satisfied despite their loss. With regard to these outcomes, the question of Levy et al. [65] about "what to share, with whom, when, and under which condition" (p. 642) is sufficiently answered in the case of the LCT to keep the alliance alive. When it comes to the overall evaluation of the LCT, it is possible to say in summary that only some bonus partners are not satisfied. In other words, even though the suppliers' market performance tends to be enhanced or not to be enhanced only slightly, the suppliers are still pleased. Thus, it is suggested that the coopetition in general works, despite the prevalence of several minor and medium issues and challenging cross-sector relationships. The suppliers predominantly reach their declared aims. In addition, almost all LCT participants would highly recommend the card. Hence, in this connection, the statement of Walley [89] could apply: " $(\ldots$ ) the interests of both the companies and the customers that they supply are best served by a coopetitive balance of both competition and cooperation" (p. 16), while, at the same time, the risk of collusion is minor [89-91]. Concluding, the coopetitive LCT alliance is more than a "double-edged sword" (p. 2060) [92], as Bouncken and Fredrich describe it.

\section{Conclusions}

This research examines a coopetitive alliance at a tourism destination, whose suppliers conjointly created a leisure card for locals. The outcomes show that the coopetition's members joined the alliance of the leisure card due to different reasons (Research Question 1), experience hugely diverse effects (Research Questions 2), and yet evaluate the alliance rather positively in general (Research Question 3). On the one hand, some of the suppliers saw themselves forced to join the alliance due to economic or political pressure, and on the other hand, those who joined on a voluntary basis mainly did so to attract more local visitors independently from their stakeholders (Corp. P, Corp. P/G, Corp G.). Regarding the effects, the LCT alliance participants report either no or only minor financial impacts-apart from some exceptions-but overwhelmingly state they experience more visits and a certain marketing effect. Finally, due to the various shareholders of the suppliers-private, governmental, or mixed forms-the economic impact is evaluated unequally: governmental suppliers accept the financial loss due to their welfare orientation, while private suppliers partly suffer from the income distributions regulations. However, in bad seasons, the fixed profit-sharing can be seen as a form of financial protection; in good seasons, as a profit limitation. However, the financial situation of the suppliers differs widely and the alliance seems to be sufficient only due to the financial independence of the governmental suppliers. 


\subsection{Research Contribution}

Overall, this study in general, the described approach, and the relevant results extend the literature in four directions: firstly, the present study contributes to the existing literature regarding cross-sector as well as same-sector coopetition. This is important as the literature claims a lack of knowledge in this field $[67,68]$. Secondly, the LCT alliance provides a unique example of coopetition embedded in a touristic context but focused on a local target audience. It extends the coopetition literature as it gives insight into a cooperative-dominant [47] alliance placed in the leisure sector. However, this statement needs to be seen from the appropriate perspective: on the one hand, the suppliers work together in terms of the resource (target-group) "residents" and share the profits (cooperative-dominant coopetition); but on the other hand, a major part of the suppliers also compete for tourists at the same time. In other words, coopetition within the alliance is double-sided. The fact that the LCT suppliers compete for tourists and cooperate regarding locals as a target group, manifests a first-level coopetition [85], and a second-level coopetition is created as they cooperate with regard to the leisure card and compete for the thereby-made profit, as shown in Figure 1. Thirdly, the literature lacks research investigating forms of coopetitions, especially those based on card-systems, even though coopetition in the context of tourism (especially with regard to DMOs) and destination cards themselves have been researched widely. Fourthly, the analytical framework provides a summary of the processes within the strategic leisure alliance. This illustration allows a certain analytical generalization, but should be extended to other industries to verify the content. However, it adds a concrete example of the underlying mechanisms to the literature of such cards (orientation towards residents as well as towards welfare). Research regarding leisure cards is very limited [3], and to our best knowledge, coopetition in particular has not been studied from of this point of view yet. Furthermore, the socio-cultural perspective of coopetition is generally comparable to a black box [90], and therefore, our approach allows at least a first insight.

\subsection{Implications}

Regarding its several implications, both for managers and for policymakers, this study contributes to the literature in different ways: Firstly, the LCT meets the claims of Collins [3] in terms of a leisure card, despite its private management. In fact, the demand for the merit good "leisure" (in the form of physical activity or in terms of education) is increased due to the LCT. From a governmental perspective, the whole concept of the LCT is worthwhile, mainly because the product is a merit good. In this respect, the LCT may be a promising pioneer and the present alliance obviously tends to find the right synergies between public and private corporations [32]. Secondly, the fact that existing, partly touristic infrastructure experiences a higher number of local visitors is elementary for the purpose of sustainability; in other words, the resource utilization is increased. This advantage may be useful for policymakers and managers when it comes to developing new resource-friendly strategies. Thirdly, from an individual supplier's perspective, participating in such alliances does not lead to better market performance in terms of profit. This results from the two-sided distribution of income. The high demand for the card can probably be explained by its relatively low price, but the additional costs become apparent in the reduced economies of scale of some suppliers. Despite this, the LCT creates a relatively un-bureaucratic alliance, allows large companies to use free capacities, and guarantees the survival of small companies in hard times. Overall, both profit-oriented and welfare-oriented corporations may experience a marketing effect and more visits. In the future, corporations should take these benefits into account when elaborating similar plans.

\subsection{Limitations and Future Research Directions}

Although the contribution of this study is evident, it is not free of limitations. Concerning the research perspective, an in-depth qualitative method is particularly efficient when little or nothing is known about an existing phenomenon [93]. Therefore, the approach we used seems to meet the 
requirements. Nevertheless, the low external validity is a drawback of this method [31]. In general, corporations who are part of the tourism industry highly depend on the governmental regulations [11]. Thus, our results are applicable only to a certain degree. We can show tendencies only, which in turn completely depend on the suppliers' perspectives.

In regard to future research directions, we believe our study has given some important insights, but, due to the complexity of this topic, it was not able to provide details about some fields of interest: the relationships between medium-sized and small corporations in a leisure-based coopetition, which can be found in the case study of the LCT, should be analyzed more in depth. Also, the cultural similarity of the actors, which is given in our case-study, was not in the focus of this research and thus could become a central theme of further investigations. Finally, we would like to stress the importance of analyzing the consumer perspective of the entire issue, examining the advantages and disadvantages a coopetition such as the LCT provides for the consumers. Thus, we encourage scholars to continue researching in this field, choosing also quantitative approaches or even mixed methods and including also the consumers' point of view.

To sum up, intentional coopetition in the form of a leisure card may be a promising option to raise a local community's welfare and may be partly beneficial for the participating corporations at the same time. This fact should also be kept in mind in the context of discussions regarding "overtourism" and thus open a new research field. Overall, the LCT may present a tool for practitioners, based on the concept of coopetition from a suppliers' perspective, and should enhance scholars-as previously mentioned-to carry out research in this field. Furthermore, future research may take the term "quality of life" into account, since the LCT experiences increasing demand.

Supplementary Materials: The following are available online at http:/ /www.mdpi.com/2071-1050/10/5/1447/ s1, Summary of the key outcomes of Phase 1-3.

Author Contributions: M.Sc. and M.Se. conceived and designed the research, developed the analysis, and wrote the paper. P.S. managed the data collection; M.P. reviewed the article.

Funding: This research received no external funding.

Acknowledgments: We would like to thank the students of the Bachelor's Program Economy, Health and Sport Tourism for participating in this research project. We would also like to thank the Office of the Vice Rector for Research of the University of Innsbruck for its support.

Conflicts of Interest: The authors declare no conflict of interest.

\section{References}

1. Steinbach, J. Tourismus: Einführung in das Räumlich-Zeitliche System; Oldenbourg: München, Germany, 2003.

2. Borchert, R. Destination Cards-Eine ordnungspolitische Betrachtung eines Angebots von Destinationen. In Incomingtourismus, 1st ed.; Bochert, R., Ed.; DUV Deutscher Universitäts-Verlag: Wiesbaden, Germany, 2006; pp. 76-96.

3. Collins, M.F. Leisure Cards in England: An Unusual Combination of Commercial and Social Marketing? Soc. Mark. Q. 2011, 17, 20-47. [CrossRef]

4. Zoltan, J.; Masiero, L. The relation between push motivation and activity consumption at the destination within the framework of a destination card. J. Destin. Mark. Manag. 2012, 1, 84-93. [CrossRef]

5. Angeloni, S. A tourist kit 'made in Italy': An 'intelligent' system for implementing new generation destination cards. Tour. Manag. 2016, 52, 187-209. [CrossRef]

6. Zoltan, J.; McKercher, B. Analysing intra-destination movements and activity participation of tourists through destination card consumption. Tour. Geogr. 2015, 17, 19-35. [CrossRef]

7. Pechlaner, H.; Zehrer, A. (Eds.) Destination-Card-Systeme: Entwicklung, Management, Kundenbindung; Linde: Wien, Austria, 2005.

8. D'Angella, F.; Go, F.M. Tale of two cities' collaborative tourism marketing: Towards a theory of destination stakeholder assessment. Tour. Manag. 2009, 30, 429-440. [CrossRef]

9. Guiver, J.; Stanford, D. Why destination visitor travel planning falls between the cracks. J. Destin. Mark. Manag. 2014, 3, 140-151. [CrossRef] 
10. Figini, P.; Vici, L. Off-season tourists and the cultural offer of a mass-tourism destination: The case of Rimini. Tour. Manag. 2012, 33, 825-839. [CrossRef]

11. Dorn, S.; Schweiger, B.; Albers, S. Levels, phases and themes of coopetition: A systematic literature review and research agenda. Eur. Manag. J. 2016, 34, 484-500. [CrossRef]

12. Zeng, M. Managing the cooperative dilemma of joint ventures: The role of structural factors. J. Int. Manag. 2003, 9, 95-113. [CrossRef]

13. Turner, N.; Swart, J.; Maylor, H. Mechanisms for Managing Ambidexterity: A Review and Research Agenda. Int. J. Manag. Rev. 2013, 15, 317-332. [CrossRef]

14. Bengtsson, M.; Kock, S. Cooperation and competition in relationships between competitors in business networks. J. Bus. Ind. Mark. 1999, 14, 178-194. [CrossRef]

15. Brandenburger, A.; Nalebuff, B.J. Co-Opetition; Currency Doubleday: New York, NY, USA, 1996.

16. Lamoreaux, N.R. The Great Merger Movement in American Business, 1895-1904; Cambridge University Press: Cambridge, MA, USA, 1985.

17. Pate, J.L. Joint venture activity, 1960-1968. Econ. Rev. 1969, 54, 16-23.

18. Gnyawali, D.R.; He, J.; Madhavan, R. Coopetition. Promises and challenges. In 21st Century Management: A Reference Handbook; Wankel, C., Ed.; Sage Publ.: Los Angeles, CA, USA, 2008; pp. 386-398.

19. Jorde, T.M.; Teece, D.J. Innovation and cooperation: Implications for competition and antitrust. J. Econ. Perspect. 1990, 4, 75-96. [CrossRef]

20. Park, S.H.; Russo, M.V. When Competition Eclipses Cooperation: An Event History Analysis of Joint Venture Failure. Manag. Sci. 1996, 42, 875-890. [CrossRef]

21. Luo, X.; Rindfleisch, A.; Tse, D.K. Working with Rivals: The Impact of Competitor Alliances on Financial Performance. J. Mark. Res. 2007, 44, 73-83. [CrossRef]

22. Hamel, G. Competition for competence and interpartner learning within international strategic alliances. Strateg. Manag. J. 1991, 12, 83-103. [CrossRef]

23. Kim, J.; Parkhe, A. Competing and Cooperating Similarity in Global Strategic Alliances: An Exploratory Examination. Br. J. Manag. 2009, 20, 363-376. [CrossRef]

24. Ritala, P. Coopetition Strategy-When is It Successful? Empirical Evidence on Innovation and Market Performance. Br. J. Manag. 2012, 23, 307-324. [CrossRef]

25. Dittrich, K.; Duysters, G. Networking as a Means to Strategy Change: The Case of Open Innovation in Mobile Telephony. J. Prod. Innov. Manag. 2007, 24, 510-521. [CrossRef]

26. Peng, T.-J.A.; Bourne, M. The Coexistence of Competition and Cooperation between Networks: Implications from Two Taiwanese Healthcare Networks. Br. J. Manag. 2009, 20, 377-400. [CrossRef]

27. Kotzab, H.; Teller, C. Value-adding partnerships and co-opetition models in the grocery industry. Int. J. Phys. Distrib. Logist. Manag. 2003, 33, 268-281. [CrossRef]

28. Bouncken, R.B.; Gast, J.; Kraus, S.; Bogers, M. Coopetition: A systematic review, synthesis, and future research directions. Rev. Manag. Sci. 2015, 9, 577-601. [CrossRef]

29. Fong, V.H.I.; Wong, I.A.; Hong, J.F.L. Developing institutional logics in the tourism industry through coopetition. Tour. Manag. 2018, 66, 244-262. [CrossRef]

30. Weidenfeld, A.; Butler, R.; Williams, A.M. Competition in the Visitor Attraction Sector; Routledge: Abingdon, UK, 2016.

31. Della Corte, V.; Aria, M. Coopetition and sustainable competitive advantage. The case of tourist destinations. Tour. Manag. 2016, 54, 524-540. [CrossRef]

32. Kylänen, M.; Mariani, M.M. Unpacking the temporal dimension of coopetition in tourism destinations: Evidence from Finnish and Italian theme parks. Anatolia 2012, 23, 61-74. [CrossRef]

33. Chim-Miki, A.F.; Batista-Canino, R.M. The coopetition perspective applied to tourism destinations: A literature review. Anatolia 2017, 28, 381-393. [CrossRef]

34. Išoraitè, M. Importance of Strategic Alliances in Company's Activity. Intellect. Econ. 2009, 1, $39-46$.

35. Mione, A. When entrepreneurship requires coopetition: The need for standards in the creation of a market. Int. J. Entrep. Small Bus. 2009, 8, 92-109. [CrossRef]

36. Ritala, P.; Hurmelinna-Laukkanen, P. What's in it for me? Creating and appropriating value in innovation-related coopetition. Technovation 2009, 29, 819-828. [CrossRef] 
37. Cairo, R. Co-Opetition and Strategic Business Alliances in Telecommunications: The Cases of BT, Deutsche Telekom and Telefonica de Espana. Ph.D. Thesis, London School of Economics and Political Science, London, UK, 2006.

38. Clarke-Hill, C.; Li, H.; Davies, B. The paradox of co-operation and competition in strategic alliances: Towards a multi-paradigm approach. Manag. Res. News 2003, 26, 1-20. [CrossRef]

39. Mention, A.-L. Co-operation and co-opetition as open innovation practices in the service sector: Which influence on innovation novelty? Technovation 2011, 31, 44-53. [CrossRef]

40. Ritala, P.; Sainio, L.-M. Coopetition for radical innovation: Technology, market and business-model perspectives. Technol. Anal. Strateg. Manag. 2014, 26, 155-169. [CrossRef]

41. Emden, Z.; Calantone, R.J.; Droge, C. Collaborating for New Product Development: Selecting the Partner with Maximum Potential to Create Value. J. Prod. Innov. Manag. 2006, 23, 330-341. [CrossRef]

42. Lado, A.A.; Boyd, N.G.; Hanlon, S.C. Competition, Cooperation, and the Search for Economic Rents: A Syncretic Model. Acad. Manag. Rev. 1997, 22, 110. [CrossRef]

43. Quintana-García, C.; Benavides-Velasco, C. Cooperation, competition, and innovative capability: A panel data of European dedicated biotechnology firms. Technovation 2004, 24, 927-938. [CrossRef]

44. Powell, W.W.; Koput, K.W.; Smith-Doerr, L. Interorganizational Collaboration and the Locus of Innovation: Networks of Learning in Biotechnology. Adm. Sci. Q. 1996, 41, 116. [CrossRef]

45. M'Chirgui, Z. The economics of the smart card industry: Towards coopetitive strategies. Econ. Innov. New Technol. 2005, 14, 455-477. [CrossRef]

46. Dagnino, G.B.; Rocco, E. (Eds.) Coopetition Strategy: Theory, Experiments and Cases; Routledge: London, UK; New York, NY, USA, 2009.

47. Bengtsson, M.; Kock, S. “Coopetition” in Business Networks-To Cooperate and Compete Simultaneously. Ind. Mark. Manag. 2000, 29, 411-426. [CrossRef]

48. Belderbos, R.; Carre, M.; Lokshin, B. Cooperative R\&D and firm performance. Res. Policy 2004, 33, 1477-1492. [CrossRef]

49. Tether, B.S. Who co-operates for innovation, and why: An empirical analysis. Res. Policy 2002, 31, 947-967. [CrossRef]

50. Fjeldstad, Ø.D.; Becerra, M.; Narayanan, S. Strategic action in network industries: An empirical analysis of the European mobile phone industry. Scand. J. Manag. 2004, 20, 173-196. [CrossRef]

51. Spiegel, M. Coopetition in the Telecommunications Industry. In Obtaining the Best from Regulation and Competition; Crew, M.A., Spiegel, M., Eds.; Kluwer: New York, NY, USA, 2005; Volume 47, pp. 93-108.

52. Garrette, B.; Dussauge, P.; Mitchell, W. Learning from Competing Partners: Outcomes and Durations of Scale and Link Alliances in Europe, North America and Asia. Strateg. Manag. J. 2000, 21, 99-126.

53. Gomes-Casseres, B. Group versus group: How alliance networks compete. Harv. Bus. Rev. 1994, 72, $62-66$.

54. Möller, K.; Rajala, A. Rise of strategic nets-New modes of value creation. Ind. Mark. Manag. 2007, 36, 895-908. [CrossRef]

55. Ritala, P. Is coopetition different from cooperation? The impact of market rivalry on value creation in alliances. IJIPM 2009, 3, 39. [CrossRef]

56. Knudsen, M.P. The Relative Importance of Interfirm Relationships and Knowledge Transfer for New Product Development Success. J. Prod. Innov. Manag. 2007, 24, 117-138. [CrossRef]

57. Robert, F.; Marques, P.; Le Roy, F. Coopetition between SMEs: An empirical study of French professional football. Int. J. Entrep. Small Bus. 2009, 8, 23-43. [CrossRef]

58. Morris, M.H.; Kocak, A.; Ozer, A. Coopetition as a Small Business Strategy: Implications for Performance. J. Small Bus. Strategy 2007, 18, 35-56.

59. Neyens, I.; Faems, D.; Sels, L. The impact of continuous and discontinuous alliance strategies on startup innovation performance. IJTM 2010, 52, 392. [CrossRef]

60. Peng, T.-J.A.; Pike, S.; Yang, J.C.-H.; Roos, G. Is Cooperation with Competitors a Good Idea? An Example in Practice. Br. J. Manag. 2012, 23, 532-560. [CrossRef]

61. Le Roy, F.; Sanou, F.H. Does Coopetition Strategy Improve Market Performance? An Empirical Study in Mobile Phone Industry. J. Econ. Manag. 2014, 17, 63-94.

62. Lorgnier, N.; CheJen, S. Considering coopetition strategies in sport tourism networks: A look at the nonprofit nautical sports clubs on the northern coast of France. Eur. Sport Manag. Q. 2014, 14, 87-109. [CrossRef]

63. Simmonds, B. Trends in public/private sector partnerships. J. Retail Leis. Prop. 2000, 1, 66-74. [CrossRef] 
64. Shaw, S.; Allen, J.B. "It basically is a fairly loose arrangement ... and that works out fine, really". Analysing the Dynamics of an Interorganisational Partnership. Sport Manag. Rev. 2006, 9, 203-228. [CrossRef]

65. Levy, M.; Loebbecke, C.; Powell, P. SMEs, co-opetition and knowledge sharing: The role of information systems. Eur. J. Inf. Syst. 2003, 12, 3-17. [CrossRef]

66. Thomason, S.J.; Simendinger, E.; Kiernan, D. Several determinants of successful coopetition in small business. J. Small Bus. Entrep. 2013, 26, 15-28. [CrossRef]

67. Babiak, K. Determinants of Interorganizational Relationships: The Case of a Canadian Nonprofit Sport Organization. J. Sport Manag. 2007, 21, 338-376. [CrossRef]

68. Ritala, P.; Laukkanen, P.H.; Blomqvist, K. Tug of war in innovation-Coopetitive service development. IJSTM 2009, 12, 255. [CrossRef]

69. Kylänen, M.; Rusko, R. Unintentional coopetition in the service industries: The case of Pyhä-Luosto tourism destination in the Finnish Lapland. Eur. Manag. J. 2011, 29, 193-205. [CrossRef]

70. Gomes-Casseres, B. Alliance Strategies of Small Firms. Small Bus. Econ. 1997, 9, 33-44. [CrossRef]

71. Ring, P.S.; Van de Ven, A.H. Structuring cooperative relationships between organizations. Strateg. Manag. J. 1992, 13, 483-498. [CrossRef]

72. Fenzl, T.; Mayring, P. Qualitative Inhaltsanalyse. In Handbuch Methoden der Empirischen Sozialforschung; Baur, N., Blasius, J., Eds.; Springer: Wiesbaden, Germany, 2014; pp. 543-556.

73. Dagnino, G.B.; Padula, G. Coopetition strategic: Towards a new kind of interfirm dynamics. In Proceeding of the 2th Annual Conference of the European Academy of Management, EURAM 2002, Stockholm, Sweden, 9-11 May 2002; pp. 1-32.

74. Luo, Y. A coopetition perspective of MNC-host government relations. J. Int. Manag. 2004, 10, $431-451$. [CrossRef]

75. MacLean, J.; Cousens, L.; Barnes, M. Look Who's Linked with Whom: A Case Study of One Community Basketball Network. J. Sport Manag. 2011, 25, 562-575. [CrossRef]

76. Webster, C.M.; Morrison, P.D. Network Analysis in Marketing. Australas. Mark. J. AMJ 2004, 12, 8-18. [CrossRef]

77. Bonel, E.; Rocco, E. Coopeting to Survive; Surviving Coopetition. Int. Stud. Manag. Organ. 2007, 37, 70-96. [CrossRef]

78. Prévot, F. Coopétition et management des compétences: Coopetition and competence management. Rev. Fr. Gest. 2007, 176, 183-202. [CrossRef]

79. Stockdale, S.; Williams, S. Leading a small business? No, it's a rugby club! Ind. Commer. Train. 2007, 39, 339-342. [CrossRef]

80. Bengtsson, M.; Johansson, M.; Näsholm, M.; Raza-Ullah, T. A systematic review of coopetition: Levels and effects on different levels. In Proceedings of the 13th Annual Conference of the European Academy of Management, EURAM 2013, Istanbul, Turkey, 26-29 June 2013.

81. Arkes, H.R.; Blumer, C. The psychology of sunk cost. Organ. Behav. Hum. Decis. Process. 1985, 35, $124-140$. [CrossRef]

82. Czakon, W.; Mucha-Kuś, K.; Sołtysik, M. Coopetition Strategy-What is in It for All? Int. Stud. Manag. Organ. 2016, 46, 80-93. [CrossRef]

83. Oum, T.H.; Park, J.-H.; Kim, K.; Yu, C. The effect of horizontal alliances on firm productivity and profitability: Evidence from the global airline industry. J. Bus. Res. 2004, 57, 844-853. [CrossRef]

84. Hsieh, Y.-H.; Lin, Y.-T.; Yuan, S.-T. Expectation-based coopetition approach to service experience design. Simul. Model. Pract. Theory 2013, 34, 64-85. [CrossRef]

85. Dowling, M.J.; Roering, W.D.; Carlin, B.A.; Wisnieski, J. Multifaceted Relationships under Coopetition. J. Manag. Inq. 1996, 5, 155-167. [CrossRef]

86. Gnyawali, D.R.; Park, B.J.R. Co-opetition between giants: Collaboration with competitors for technological innovation. Res. Policy 2011, 40, 650-663. [CrossRef]

87. Horch, H.-D. Does Government Financing have a Detrimental Effect on the Autonomy of Voluntary Associations? Evidence from German Sports Clubs. Int. Rev. Sociol. Sport 1994, 29, 269-285. [CrossRef]

88. Pellegrin-Boucher, E.; Le Roy, F.; Gurău, C. Coopetitive strategies in the ICT sector: Typology and stability. Technol. Anal. Strateg. Manag. 2013, 25, 71-89. [CrossRef]

89. Walley, K. Coopetition: An introduction to the subject and an agenda for research. Int. Stud. Manag. Organ. 2007, 37, 11-31. [CrossRef] 
90. Mariani, M.M. Coopetition as an Emergent Strategy: Empirical Evidence from an Italian Consortium of Opera Houses. Int. Stud. Manag. Organ. 2007, 37, 97-126. [CrossRef]

91. Rusko, R. Exploring the concept of coopetition: A typology for the strategic moves of the Finnish forest industry. Ind. Mark. Manag. 2011, 40, 311-320. [CrossRef]

92. Bouncken, R.B.; Fredrich, V. Coopetition: Performance Implications and Management Antecedents. Int. J. Innov. Manag. 2012, 16, 1250028. [CrossRef]

93. Eisenhardt, K.M. Building Theories from Case Study Research. Acad. Manag. Rev. 1989, 14, 532. [CrossRef] 